\title{
In Vivo Constriction of the Ductus Arteriosus by Nonsteroidal Antiinflammatory Drugs in Near-Term and Preterm Fetal Rats
}

\author{
KAZUO MOMMA AND ATSUYOSHI TAKAO \\ Department of Pediatric Cardiology, The Heart Institute of Japan, Tokyo Women's Medical College. \\ Tokyo, Japan
}

\begin{abstract}
Herein we report age differences of in vivo constriction of the fetal ductus arteriosus by nonsteroidal antiinflammatory drugs in near-term and preterm rats. Two potent nonsteroidal antiinflammatory drugs, indomethacin and flurbiprofen, were studied in preterm (19th and 20th day) and near-term ( 21 st day) rats, whose gestational period was 21.5 days. The time course of fetal ductus constriction was studied on the 20th (preterm fetus) and the 21 st (near-term fetus) days of gestation with indomethacin $(1 \mathrm{mg} / \mathrm{kg}, 10 \mathrm{mg} / \mathrm{kg})$ and flurbiprofen $(10 \mathrm{mg} / \mathrm{kg})$. In addition, $5 \mathrm{mg} / \mathrm{kg}$ of indomethacin was used on the $21 \mathrm{st}$ day. Maximal ductal constriction was noticed $8 \mathrm{~h}$ after administration. Constriction of the ductus was significantly weaker on the 20 th day than on the 21 st day in all three studies including indomethacin $1 \mathrm{mg} / \mathrm{kg}, 10 \mathrm{mg} / \mathrm{kg}$, and flurbiprofen, $10 \mathrm{mg} / \mathrm{kg}$. Dose-response curves were studied at $4 \mathrm{~h}$ following administration of indomethacin on the 19th, 20th, and 21st days, and flurbiprofen on the 20th and 21 st days. With both drugs, the ductus constricted more vigorously on the 21 st day than on the 20 th or 19 th day. These studies showed a weaker constrictive response of the ductus to nonsteroidal antiinflammatory drugs in the preterm fetus than in the near-term fetus. Twenty-four $h$ after administration of indomethacin on the 20th day, the fetal ductus was dilated, although its plasma indomethacin concentration was high and comparable with that obtained $4 \mathrm{~h}$ after administration. These results show that the response of the fetal ductus to indomethacin decreased further at $24 \mathrm{~h}$ after administration to preterm rats. (Pediatr Res 22:567-572, 1987)
\end{abstract}

\section{Abbreviations}

DA, ductus arteriosus

NSAID, nonsteroidal antiinflammatory drug

PA, pulmonary artery

During the last decade, evidence has been accumulated showing that the fetal DA remains patent due to endogenous prostaglandins $(1-11)$. This has been proved in lambs $(1-6)$, rats $(7,8)$, rabbits (8), and humans (9-11). In lambs, the mechanism works in midterm as well as in late-term fetuses $(12,13)$. In humans, only a few pre-term cases of persistent pulmonary hypertension

Received October 1, 1986; accepted June 30, 1987.

Correspondence and for reprint requests: Kazuo Momma, M.D. The Heart Institute of Japan, Tokyo Women's Medical College. Kawadacho 8-1, Shinjukuku, Tokyo 162, Japan.

Supported by a grant in aid from the Ministry of Education, Science, and Culture of Japan and by the Japan Promotion Society for Cardiovascular Diseases. of the newborn were reported following maternal ingestion of a NSAID (10), and nothing is known about ductal reactivity in midtrimester to NSAIDs, which inhibit cyclooxygenase and decreases endogenous prostaglandins. However, in rats, ductal constriction by aspirin and indomethacin occurs only in near-term fetuses, and it is weak in preterm fetuses $(7,14)$. Very little is known about this age-related reactivity of the fetal ductus in rats and nothing is known about its mechanism despite possible clinical importance. This prompted us to study further the constriction of fetal DA following administration of NSAIDs to near-term and preterm pregnant rats.

\section{MATERIALS AND METHODS}

Virgin Wistar rats (pregnancy period 21.5 days) were mated overnight from 1700 to $0900 \mathrm{~h}$, and the presence of sperm on vaginal smears dated the zero day of pregnancy. These rats were fed commercial solid food and water. Drugs were administered through an orogastric tube in a suspension with $2 \mathrm{ml}$ water containing $5 \%$ arabic gum at $0900 \mathrm{~h}$ on the $19 \mathrm{th}, 20 \mathrm{th}$, or $21 \mathrm{st}$ day of pregnancy.

Fetal DA was studied using the rapid whole-body freezing technique, as reported previously (14-17). Briefly, the rat was sacrificed by cervical dislocation, and fetuses were delivered quickly by cesarean section, and frozen quickly by immersion in acetone cooled to $-80^{\circ} \mathrm{C}$ by dry ice. The frozen fetuses of each litter were weighed to obtain the mean body weight. The frozen thorax was trimmed and sectioned at a frontal plane on a freezing microtome, and the inner diameters of the pulmonary trunk and DA were measured under a stereoscopic microscope and micrometer, as reported previously (14-17). The ratio of the inner diameter of the DA at its narrowest point to the pulmonary trunk (DA/PA) was used to evaluate the constrictive effects of the drugs.

Maternal and fetal blood were collected at the time of sacrifice for measurement of indomethacin concentrations. Maternal blood was drawn by cardiac puncture after cesarean section with a syringe containing $0.1 \mathrm{ml}(100 \mathrm{U})$ of heparin. Fetuses from each litter were divided into two groups, one for rapid wholebody freezing and the other for blood collection. Fetal blood was collected using heparin-coated funnels by a deep cut in the neck. It was collected from six to eight fetuses from the same litter and studied as one sample. Blood samples were kept at $4^{\circ} \mathrm{C}$ for one night before separation of plasma by centrifugation. Plasma samples were stored at $-20^{\circ} \mathrm{C}$ until measurement of indomethacin by gas-liquid chromatography (18).

The following six experiments were conducted. Indomethacin was studied in experiments $1,2,3$, and 4 because of its popular clinical use, its potent effect as a cyclooxygenase inhibitor, and the availability of estimations of its plasma concentrations. Flurbiprofen was studied in addition as another potent cyclooxygen- 
ase inhibitor. Constriction of the fetal ductus by these NSAIDs was studied on the 19th, 20th, and 21 st days with several doses (i.e. $0.01,0.1,1,10$, or $100 \mathrm{mg} / \mathrm{kg}$ ) by sacrificing the animal at $4 \mathrm{~h}$ after administration, as in an earlier study (14), and doseresponse curves were compared. Because an earlier study revealed that the morphology and degree of constriction of the fetal DA changed characteristically with $24 \mathrm{~h}$ following administration of indomethacin (17), reactivity of DA to the drug on different gestational days was studied at $1,4,8$, and $24 \mathrm{~h}$ after administration as in that study, using a moderate dose $(1 \mathrm{mg} / \mathrm{kg})$ of indomethacin and a high dose $(10 \mathrm{mg} / \mathrm{kg})$ of indomethacin and flurbiprofen. The high dose was studied because our preliminary study showed a loss of constricting effect at $24 \mathrm{~h}$ after administration of this dose in preterm fetuses despite persistent high plasma concentrations, and because this high dose was used in earlier studies $(7,17)$. In addition, reaction to $5 \mathrm{mg} / \mathrm{kg}$ indomethacin was studied on the 21 st day to eliminate the possible effect of lower plasma indomethacin levels in preterm fetuses following administration of $10 \mathrm{mg} / \mathrm{kg}$ indomethacin.

In experiment 1 , time courses of the fetal DA constriction and plasma indomethacin concentrations were studied following administration of $10 \mathrm{mg} / \mathrm{kg}$ indomethacin to the dams. Five to 10 dams were studied at $1,4,8$, or $24 \mathrm{~h}$ after administration on the 19 th, 20 th, and 21 st day of gestation.

In experiment 2, the time course of the fetal DA constriction and plasma indomethacin concentrations were studied following administration of $5 \mathrm{mg} / \mathrm{kg}$ indomethacin to the dam on the $21 \mathrm{st}$ day of gestation. Four to five dams were studied at $1,4,8$, or 24 $\mathrm{h}$ after administration.

In experiment 3 , time courses of the fetal DA constriction and plasma indomethacin concentrations were studied following administration of $1 \mathrm{mg} / \mathrm{kg}$ indomethacin to the dams. Five to 10 dams were studied at $1,4,8$, or $24 \mathrm{~h}$ after administration on the 20 th or 21 st day of gestation.

In experiment 4 , the relation of doses to constriction of the fetal DA was studied $4 \mathrm{~h}$ after administration of indomethacin.
Two to 10 dams were studied after administration of either 0.01 , $0.1,1,10$, or $100 \mathrm{mg} / \mathrm{kg}$ indomethacin on the $19 \mathrm{th}, 20 \mathrm{th}$, or $21 \mathrm{st}$ days of gestation.

In experiment 5 , the time course of the fetal DA constriction was studied following administration of $10 \mathrm{mg} / \mathrm{kg}$ flurbiprofen to dams. Two or three dams were studied at $1,4,8$, or $24 \mathrm{~h}$ after administration on the 20 th or 21 st day of gestation.

In experiment 6 , the relation of doses to constriction of the fetal DA was studied $4 \mathrm{~h}$ after administration of flurbiprofen. Two or three dams were studied after administration of either $0.01,0.1,1,10$, or $100 \mathrm{mg} / \mathrm{kg}$ flurbiprofen on either 20 th or $21 \mathrm{st}$ days of gestation.

As controls, fetal DA from three dams was studied on the $19 \mathrm{th}, 20 \mathrm{th}$, and $21 \mathrm{st}$ days of gestation without drug administration.

The results are expressed as means \pm SEM. Two- and 3-way analysis of variance were used and the statistical significance of differences between group means was determined by the modified $t$ statistics (19). The difference was considered to be significant if the $p$ value was less than 0.05 .

\section{RESULTS}

The results of experiments 1 and 2 are shown in Figures 1-3, the results of experiment 3 are shown in Figures 4 and 5, the results of experiment 4 are shown in Figure 6 , and the results of experiments 5 and 6 are shown in Figures 7 and 8 , respectively.

Age effects were notable in the time-course studies. As shown in Figure $2,10 \mathrm{mg} / \mathrm{kg}$ indomethacin constricted the fetal ductus of the 21 st day severely and persistently from 1 through $24 \mathrm{~h}$ after administration. However, ductal constriction by the same dosage was significantly weaker and shorter in preterm fetuses. Statistical analysis revealed that compared with the ductal constriction on the 21 st day the ductal constriction on the 19 th and 20th day was significantly weaker at $1,4,8$, and $24 \mathrm{~h}$ after administration. As shown in Figure 3, fetal plasma concentra-
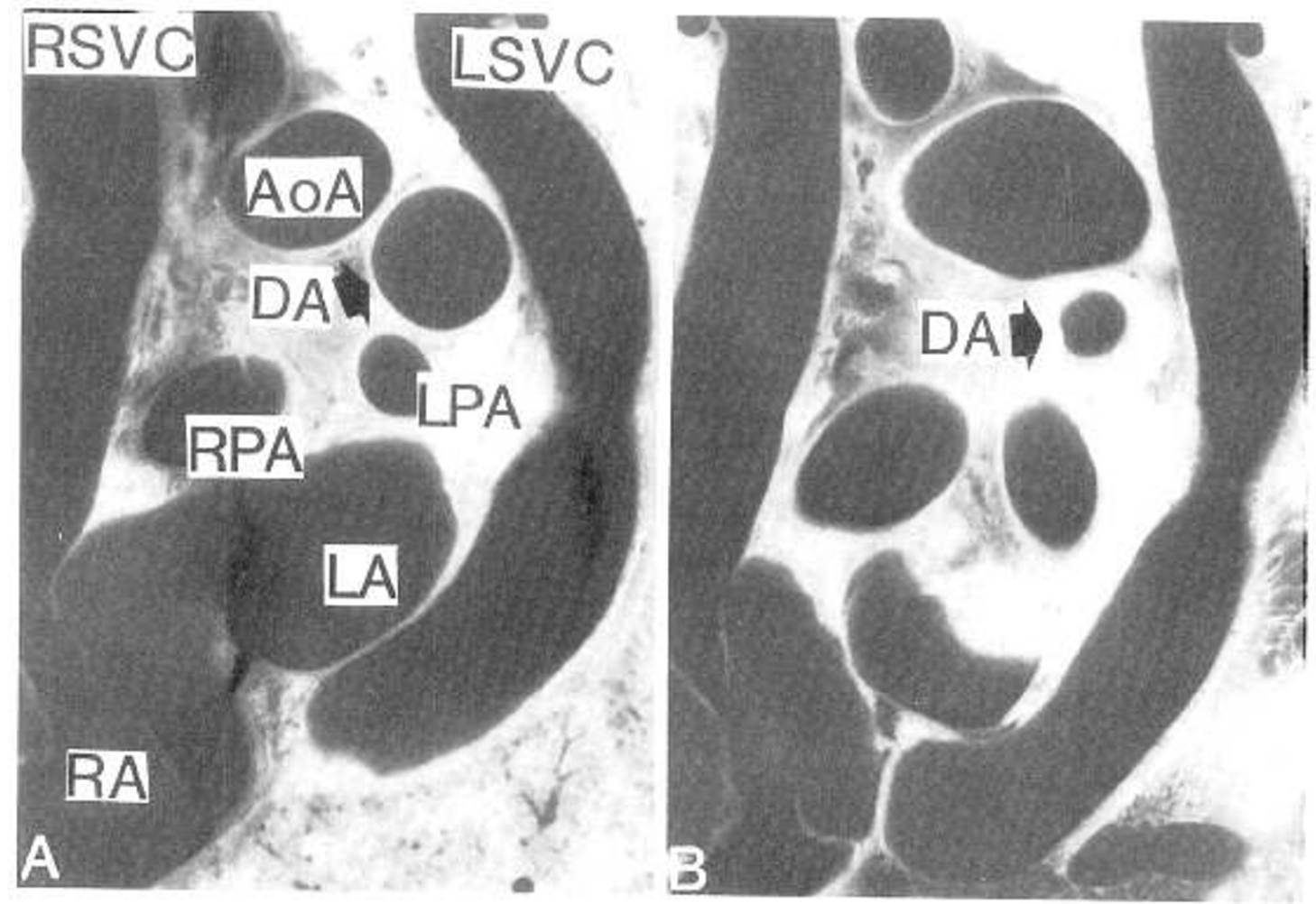

Fig. 1. Frontal sections of fetal rat DA: Note dilated DA in the control fetus on the 21 st day of gestation $(A)$ and constricted fetal DA at $24 \mathrm{~h}$ following administration of $10 \mathrm{mg} / \mathrm{kg}$ indomethacin on the 21 st day $(B) . A O A$, aortic arch; $L A$, left atrium; $L P A$, left pulmonary artery; $L S V C$, left superior vena cava; $R A$, right atrium; $R P A$, right pulmonary artery; $R S V C$, right superior vena cava. 

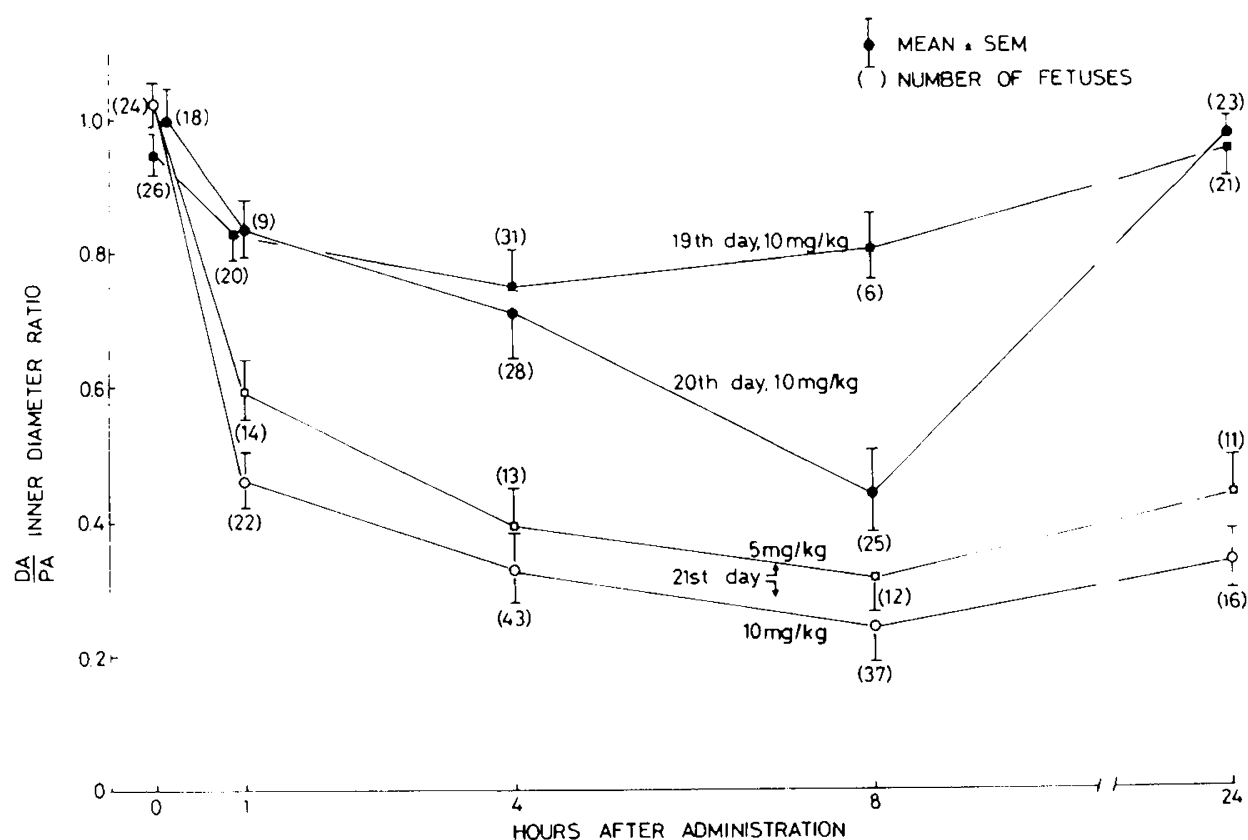

Fig. 2. Results of experiments 1 and 2. Time course of fetal DA constriction after maternal administration of $10 \mathrm{mg} / \mathrm{kg}$ indomethacin on the 19th, 20th, or $21 \mathrm{st}$ day of gestation and $5 \mathrm{mg} / \mathrm{kg}$ indomethacin on the $21 \mathrm{st}$ day. Hours after administration on the horizontal axis and DA/PA inner diameter ratio on the vertical axis. Note lesser constriction of fetal DA in preterm rats.
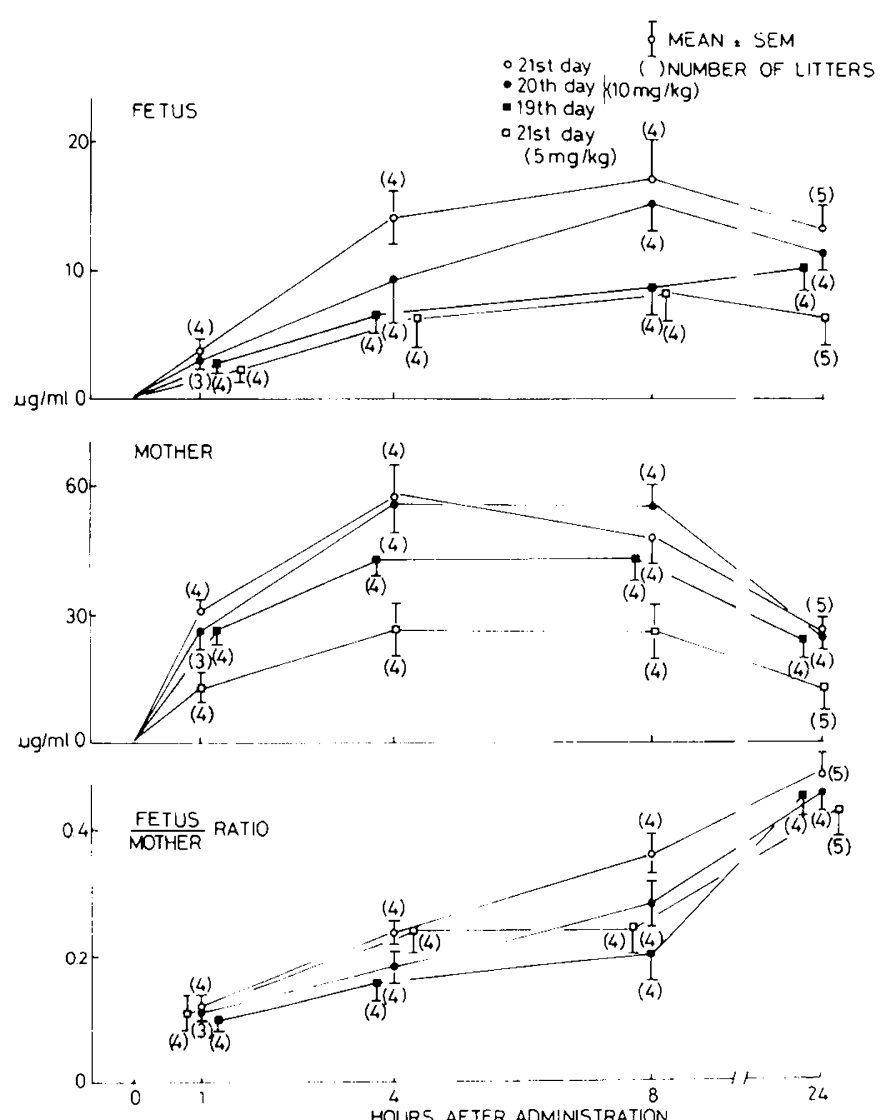

Fig. 3. Indomethacin plasma concentration of maternal and fetal paired samples in experiments 1 and 2.

tions of indomethacin were lower at 4 and $8 \mathrm{~h}$ in preterm rats compared with near-term rats, following administration of 10 $\mathrm{mg} / \mathrm{kg}$ indomethacin, but were not less than those following administration of $5 \mathrm{mg} / \mathrm{kg}$ indomethacin on the $21 \mathrm{st}$ day. Be- cause administration of $5 \mathrm{mg} / \mathrm{kg}$ indomethacin on the $21 \mathrm{st}$ day constricted the fetal ductus severely and persistently, decreased reactivity of the preterm fetal ductus was not due to lower plasma concentrations of indomethacin. At $24 \mathrm{~h}$ after administration. plasma indomethacin concentrations were at high levels in both near-term and preterm fetuses in spite of the fact that the ductus was dilated fully in the preterm rats at this time.

The same age-effects were observed in other experiments. As shown in Figure 4 , administration of $1 \mathrm{mg} / \mathrm{kg}$ indomethacin constricted the fetal ductus more severely in near-term rats than in preterm rats. Plasma concentrations of indomethacin were about $1 / 10$ of those following administration of $10 \mathrm{mg} / \mathrm{kg}$ indomethacin as shown in Figure 5. The same age-effects were also observed with another NSAID, flurbiprofen. As shown in Figure 6 , ductal constriction following administration of $10 \mathrm{mg} / \mathrm{kg}$ flurbiprofen was severe and persistent on the 21 st day, but it was much weaker and shorter on the 20 th day.

The age effects are clearly shown in dose-response curves in Figures 7 and 8 . As shown in Figure 7, on the 21 st day the doseresponse curves $4 \mathrm{~h}$ after administration of indomethacin show more constriction of the ductus as the dose increases. However, on the 19th or 20th day, the ductal constriction was slight even with a large dose, and the differences between the values of the 21 st day and those of the 19th or 20th day were significant statistically at doses of 1,10 , and $100 \mathrm{mg} / \mathrm{kg}$. Approximately the same results were obtained with flurbiprofen. As was shown in Figure 8 , fetal ductal constriction by flurbiprofen was much stronger on the 21 st day than on the 20th day. Body weights of control fetuses are shown in table 1.

\section{DISCUSSION}

The sensitivity of premature fetal DA to indomethacin or other NSAIDs is controversial, and completely different results have been reported both clinically and experimentally. In an in vitro experiment with ductal strips of fetal lamb, preterm DA constricted more than near-term DA in response to indomethacin (13) or to ibuprofen (12) in a high oxygen environment. However, in intrauterine fetal lambs in vivo and in a low oxygen environment, preterm and near-term fetuses were equally sensitive to indomethacin (6). 


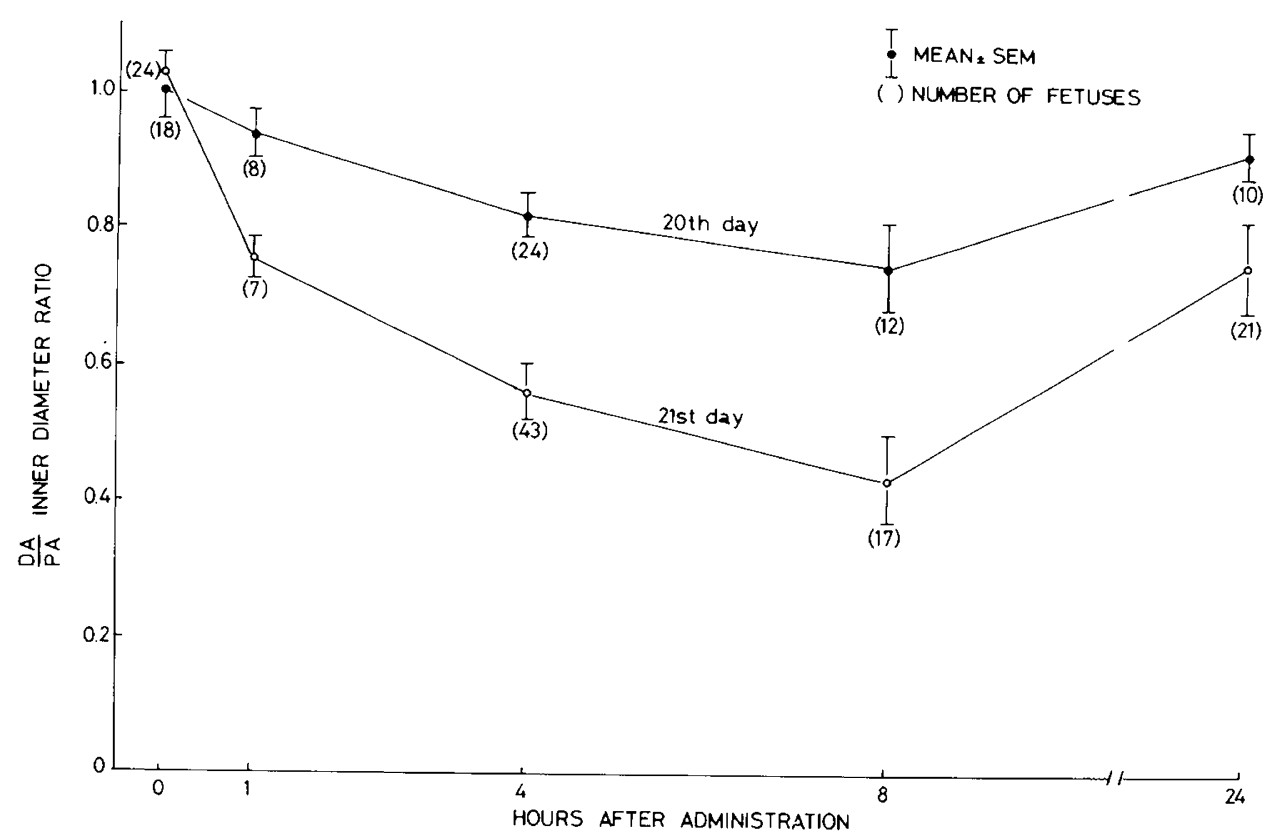

Fig. 4. Results of experiment 3. Time course of fetal DA constriction by maternal administration of $1 \mathrm{mg} / \mathrm{kg}$ indomethacin on the 20 th or 21 st day of gestation.
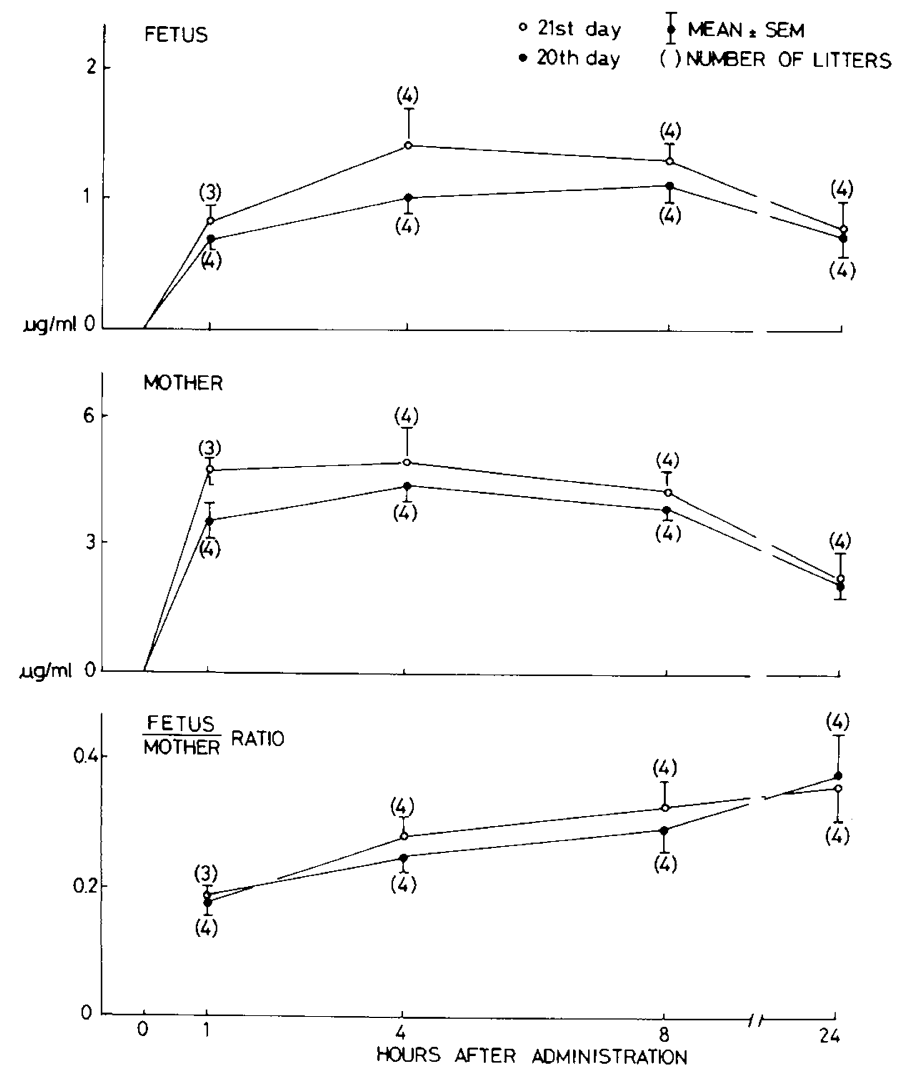

Fig. 5. Indomethacin plasma concentration of maternal and fetal paired samples in experiment 3.

Sharpe $e t$ al. (8) studied preterm and term rat fetuses following administration of indomethacin to the dam. They noticed the most prominent constriction of the fetal DA on the 22nd day of gestation, only modest constriction on the 20th day, and no constriction on the 18 th day. The present study confirmed their results with additional data of dose-response curves and plasma indomethacin concentrations. The present study with flurbiprofen, another potent inhibitor of cyclooxygenase, provides addi- tional evidence that the DA in the preterm fetal rat is less sensitive to inhibition of cyclooxygenase than the DA in the near-term fetal rat. This is in sharp contrast to the results of the in vitro fetal lamb experiments, but because of the different experimental methods, we cannot conclude that the different results were due to species difference.

The reason is not clear why the fetal ductus is more refractory to cyclooxygenase inhibitors in the preterm rat. Possibly the ductus is more immature structurally or metabolically in the preterm fetal rat, but these possibilities remain to be studied.

Clinically, cases with fetal ductal constriction and neonatal persistent pulmonary hypertension were reported both in preterm infants of $30 \mathrm{wk}$ gestation (10) and in a full-term infant (9). Since the introduction of indomethacin therapy for patent ductus arteriosus in premature infants $(20,21)$, factors related to the failure of indomethacin to close the patent ductus have been analyzed. There is some evidence showing that infants with a very low birth weight showed only a transient response to indomethacin, or none at all $(22,23)$. The oxygen environment of the ductus tissue in these infants is much higher than in fetal DA. Although this difference of oxygen environment may have some modifying effect on the sensitivity of the ductus to indomethacin, the results of this experiment in fetal rats accord well with the clinical observations in that preterm fetal DA is less sensitive to indomethacin than near-term fetal DA.

The present study showed that fetal DA was dilated despite a high plasma indomethacin concentration at $24 \mathrm{~h}$ following administration on the 20th day of gestation. The reason for this paradoxical phenomenon is not clear. An earlier study on fetal rats showed that the DA-constricting effects of glucocorticoids were more potent on premature fetuses than on mature ones (16). Glucocorticoids inhibit phospholipase A2, thereby inhibiting release of arachidonic acid (24), while NSAIDs inhibit cyclooxygenase. Arachidonic acid can be transformed by lipoxygenase into leukotrienes in addition to transformation into prostaglandins and thromboxanes by cyclooxygenase (25). The different effects of NSAIDs and glucocorticoids are compatible with the hypothesis that leukotrienes or other related substances work to dilate DA in preterm rats. According to this hypothesis, the dilatation of DA at $24 \mathrm{~h}$ after administration of $10 \mathrm{mg} / \mathrm{kg}$ inhibition of cyclooxygenase, accumulation of arachidonic acid, and its transformation into DA-dilating substances, which could be leukotrienes. However, work on the near-term fetal lamb 


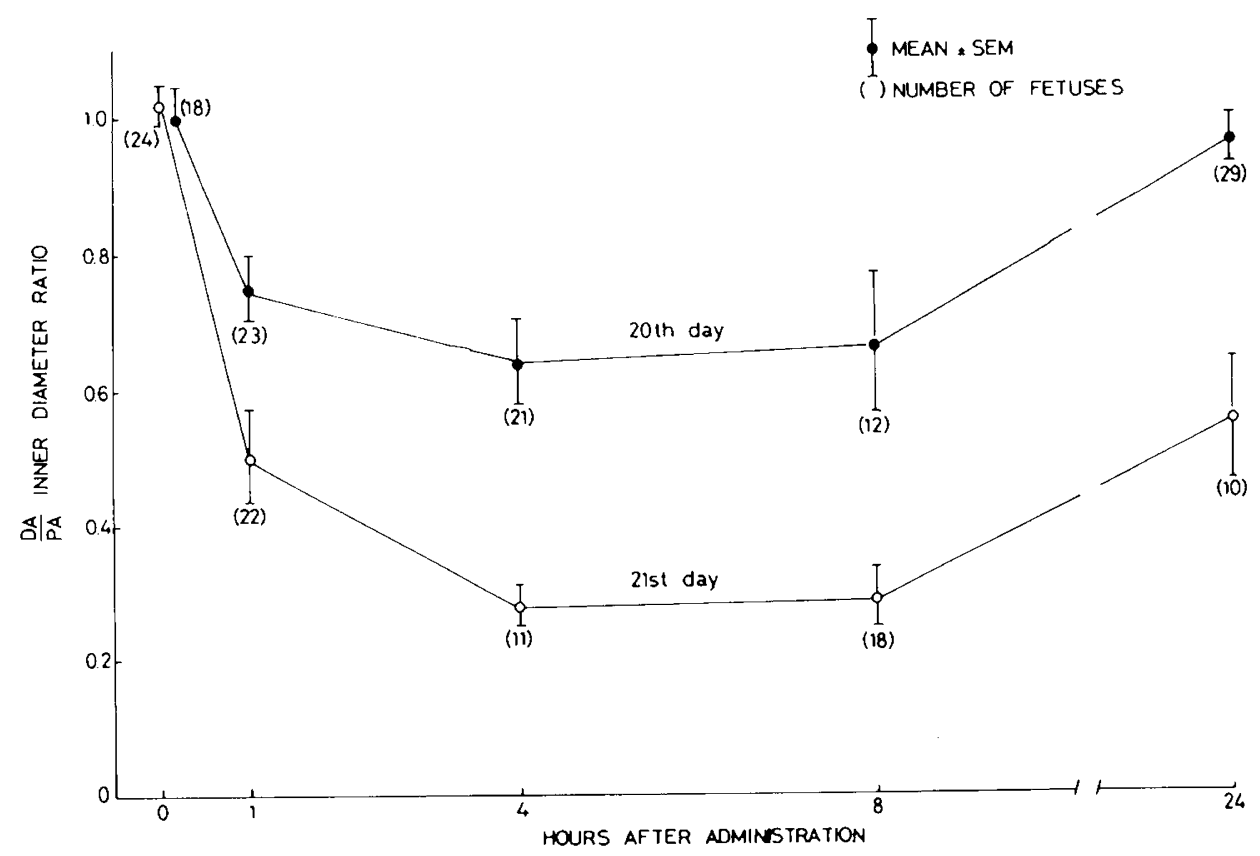

Fig. 6. Results of experiment 5. Time course of fetal DA constriction by maternal administration of $10 \mathrm{mg} / \mathrm{kg}$ flurbiprofen on the $20 \mathrm{th}$ or $21 \mathrm{st}$ day of gestation.

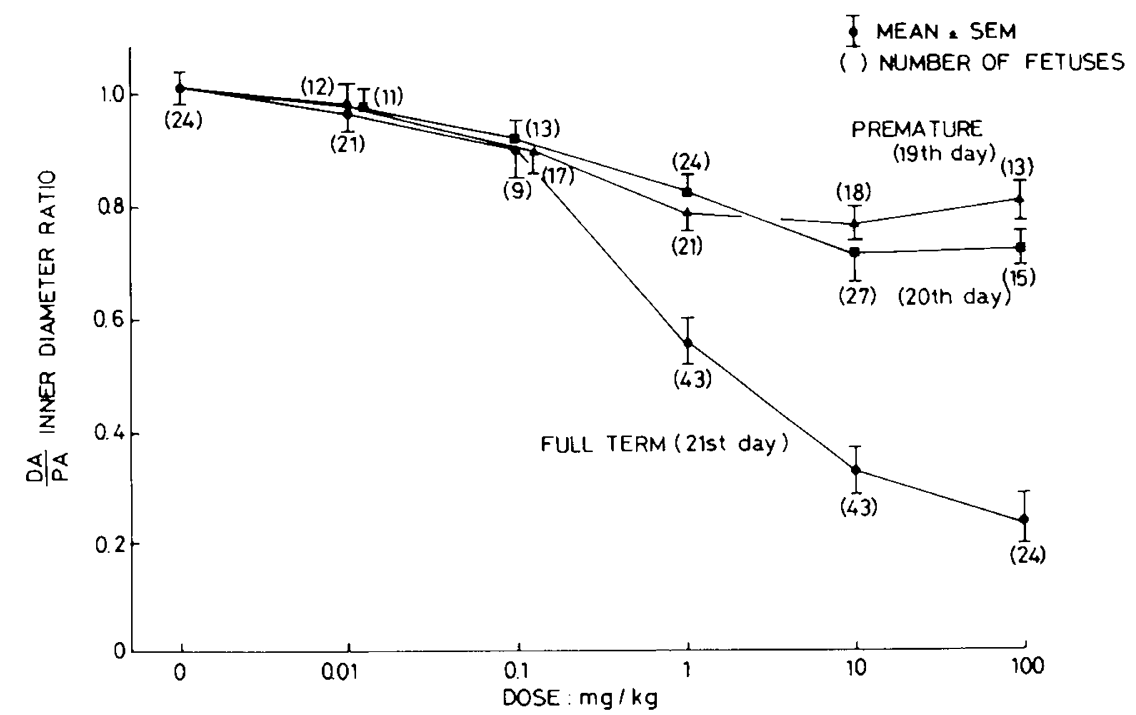

Fig. 7. Results of experiment 4. Dose response curves of fetal DA constriction by various doses of indomethacin on the 19 th, 20th, or 21 st day of gestation. Animals were sacrificed at $4 \mathrm{~h}$ following drug administration. Note that DA constriction reached a maximum at $10 \mathrm{mg} / \mathrm{kg}$ on the $20 \mathrm{th}$ day or at $1 \mathrm{mg} / \mathrm{kg}$ on the 19 th day.

be leukotrienes. However, work on the near-term fetal lamb indicates that leukotrienes have no role in the control of ductal tone (26), and our hypothesis including production of DAdilating substances other than prostaglandins in the preterm fetal DA remains speculative.

The clinical significance of this paradoxical effect of a high concentration of indomethacin to preterm fetal ductus is speculative. This effect appears with high doses such as $10 \mathrm{mg} / \mathrm{kg}$ of indomethacin, and probably is also present with the usual clinical dose. This effect could cancel the constrictive effect of indomethacin to the patent ductus of preterm infants. On the other hand, this effect could open the fetal ductus when indomethacin is administered repeatedly to preterm pregnant women.

Extrapolation from fetal rats to human fetuses is not easy because the gestational period of the rat is only 21 or 22 days. In rats, morphogenesis of the heart is completed on the 14th day of gestation (27), and the fetal heart grows in the last 7 or 8 days.
The human fetus spends 8 months after completion of its cardiac morphogenesis to birth. Therefore, 1 day in the fetal rat may correspond to 1 month in the human fetus. This simple comparison seems correct when considering the relative gain of the fetal body weight. In rats, fetal weight doubles in the last 2 days from the 19th day to the 21 st day, while human fetal weight doubles in the last 2 months. If the results of this study are extrapolated to the human fetus at a rate of 1 day to 1 month in the gestational period, the DA of a preterm baby of 7 or 8 months of gestation is presumed to be less sensitive to a NSAID such as indomethacin than the DA of near-term fetuses. Apparently more clinical and experimental studies are needed to confirm this phenomenon.

The present study showed the time course of maternal and fetal plasma concentrations of indomethacin following oral administration of a single dose. A species' difference exists in the pharmacokinetics of indomethacin; its biological half-time is unusually long in rats (28). No data are available on the phar- 


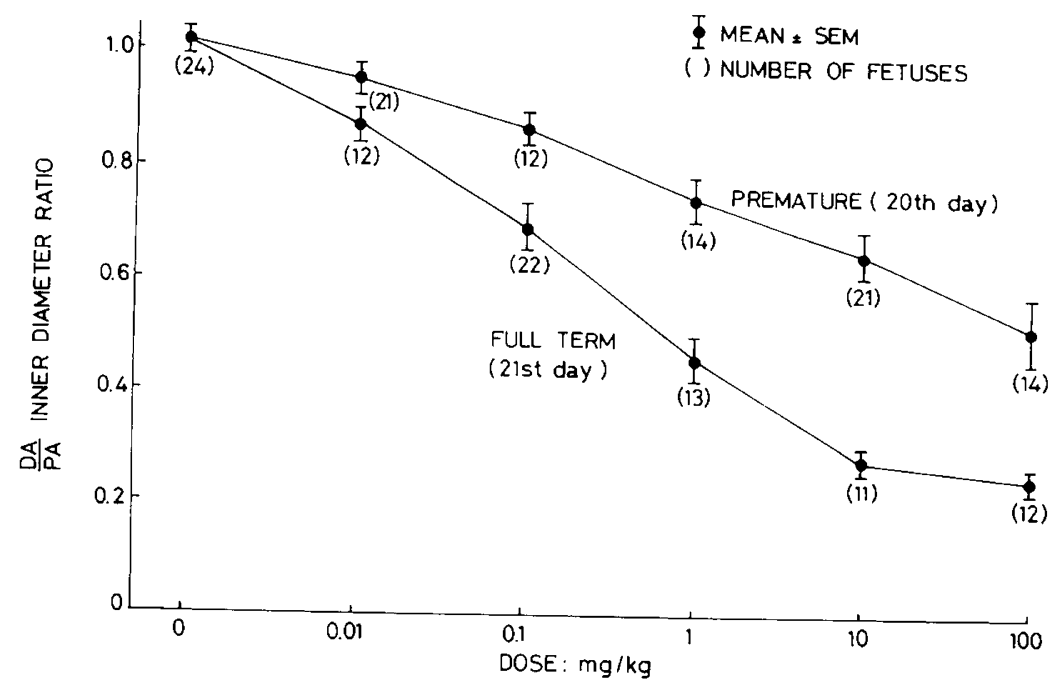

Fig. 8. Results of experiment 6. Dose response curves of fetal DA constriction by various doses of flurbiprofen on the 20 th or 21 st day of gestation. Animals were sacrificed at $4 \mathrm{~h}$ after drug administration.

Table 1. Body wt in control rat fetuses without administration of NSAID

\begin{tabular}{cc}
\hline Days of gestation & Mean \pm SD (no. of litters) \\
\hline 19 & $2.65 \pm 0.34(10)$ \\
20 & $3.89 \pm 0.43(8)$ \\
21 & $5.31 \pm 0.55(10)$ \\
22 & $6.13 \pm 0.66(4)$ \\
\hline
\end{tabular}

macokinetics of indomethacin in the human fetus following its administration to the mother. Therefore the time course of plasma indomethacin concentration in near-term and preterm rat fetuses in this study may serve as an animal model of this problem.

\section{CONCLUSION}

In the preterm fetal rat fetuses, the DA constricted less than in near-term fetuses following administration of indomethacin or flurbiprofen to the dam. It is concluded that the DA of preterm fetuses is less sensitive to inhibition of prostaglandin synthesis than that of full-term fetuses in this species. In addition, loss of the constrictive effect of a high dose of indomethacin in the preterm fetal ductus, at $24 \mathrm{~h}$ after administration, was noticed.

Acknowledgment. The authors thank Barbara Levene for editorial help.

\section{REFERENCES}

1. Coceani F, Olley PM 1980 Role of prostaglandins, prostacyclin, and thromboxanes in the control of prenatal patency and postnatal closure of the ductus arteriosus. In: Heymann MA (ed) Prostaglandins in the Perinatal Period. Their Physiological and Clinical Importance. Grune \& Stratton, New York, pp 109-114

2. Olley PM, Bodach E, Heaton J, Coceani F 1975 Further evidence implicating E-type prostaglandins in the patency of the lamb ductus arteriosus. Eur $\mathrm{J}$ Pharmacol 34:247-250

3. Heymann MA, Rudolph AM 1976 Effects of acetylsalicylic acid on the ductus arteriosus and circulation in fetal lambs in utero. Circ Res 38:418-422

4. Levin DL, Mills LJ, Parkey M, Garriott J, Campbell W 1979 Constriction of the fetal ductus arteriosus after administration of indomethacin to the pregnant ewe. J Pediatr 94:647-650

5. Clyman RI, Heymann MA, Rudolph AM 1977 Ductus arteriosus responses to prostaglandin El at high and low oxygen concentrations. Prostaglandins 13:219-223

6. Friedman WF, Printz MP, Kirkpatrick SE, Hoskins ED 1983 The vasoreactivity of the fetal lamb ductus arteriosus studied in utero. Pediatr Res 17:331337

7. Sharpe GE, Thalme B, Larsson KS 1974 Studies on closure of the ductus arteriosus. IX Ductus closure in utero by a prostaglandin synthetase inhibitor. Prostaglandins 8:363-368

8. Sharpe GE, Larsson KS, Thalme B 1975 Studies of the ductus arteriosus. XII In utero effect of indomethacin and sodium salicylate in rats and rabbits. Prostaglandins 9:585-596

9. Arcilla RA, Thilenius OG, Ranniger K 1969 Congestive heart failure from suspected ductal closure in utero. J Pediatr 75:74-78

10. Wilkinson AR, Ansley-Green A, Mitchll MD 1979 Persistent pulmonary hypertension and abnormal prostaglandin levels in preterm infants after maternal treatment with naproxen. Arch Dis Child 54:942-945

11. Levin DL 1980 Effects of inhibition of prostaglandin synthesis on fetal development, oxygenation, and the fetal circulation. In: Heymann MA (ed) Prostaglandins in the Perinatal Period. Their Physiologic and Clinical Importance. Grune \& Stratton, New York, pp 35-44

12. Coceani F, White E, Bodach E, Olley PM 1979 Age-dependent changes in the response of the lamb ductus arteriosus to oxygen and ibuprofen. Can $\mathbf{J}$ Physiol Pharmacol 57:825-831

13. Clyman RI 1978 Developmental responses to oxygen, arachidonic acid, and indomethacin in the fetal lamb ductus arteriosus in vitro. Prostaglandins Med 1:167-174

14. Momma K, Takeuchi H 1983 Constriction of fetal ductus arteriosus by nonsteroidal anti-inflammatory drugs. Prostaglandins 26:631-643

15. Momma K, Uemura S, Nishihara S, Ota Y 1980 Dilatation of the ductus arteriosus by prostaglandins and prostaglandin's precursors. Pediatr Res 14:1074-1077

16. Momma K, Nishihara S, Ota Y 1981 Constriction of the fetal ductus arteriosus by glucocorticoid hormones. Pediatr Res 15:19-21

17. Momma K, Konishi T, Hagiwara H 1985 Characteristic morphology of the constricted fetal ductus arteriosus following maternal administration of indomethacin. Pediatr Res 19:453-500

18. Helleberg A 1976 Determination of indomethacin in serum and urine by electo-capture gas-liquid chromatography. J Chromatogr 117:167-173

19. Wallenstein S. Zucker CL, Fleiss JL 1980 Some statistical methods useful in circulation research. Circ Res 47:1-9.

20. Friedman WF, Hirschklau MJ, Printz MP, Pitlick DT, Kirkpatrick SE 1976 Pharmacological closure of patent ductus arteriosus in the premature infant. N Engl J Med 295:526-529

21. Heymann MA, Rudolph AM, Silverman NH 1976 Closure of the ductus arteriosus in premature infants by inhibition of prostaglandin synthesis. $\mathrm{N}$ Engl J Med 295:530-534

22. Ivey HH, Kattwinkel J, Park TS, Krovetz LJ 1979 Failure of indomethacin to close persistent ductus arteriosus in infants weighing under 1000 grams. $\mathrm{Br}$ Heart J 41:304-307

23. Mellander M, Leheup B, Lindstrom DP, Palme C, Graham TP Jr., Stahlman MT, Cotton RB 1984 Recurrence of symptomatic patent ductus arteriosus in extremely premature infants, treated with indomethacin. $\mathrm{J}$ Pediatr 105:138-143

24. Flower RJ, Vane JR 1974 Inhibition of prostaglandin biosynthesis. Biochem Pharmacol 23:1439-1450

25. Samuelsson B, Hammarstroem S 1982 Leukotriens, a novel group of biologically active compounds. Vitam Horm 39:1-11

26. Coceani F, Jhamandas VM, Bodach E, Labuc J, Olley PM, Borgeat P 1982 Evidence against a role for lipoxygenase-derived products of arachidonic acid in the lamb ductus arteriosus. Can J Physiol Pharmacol 60:345-349

27. Sissman NJ 1970 Developmental landmarks in cardiac morphogenesis: Comparative chronology. Am J Cardiol 25:14l-148

28. Hucker HB, Zacchei AG, Cox SV, Brodie DA, Cantwell NHR 1966 Studies on the absorption, distribution and excretion of indomethacin in various species. J Pharmacol Exp Ther 153:237-249 